\title{
Predicting Managers' Organizational Productivity with Regard to Managerial Talent and Time Management
}

\author{
Mohammad Hosein Pourshanbe \\ Afsaneh Marziyeh* \\ Abede Nazari \\ Department of Education, Faculty of Educational Sciences and Psychology \\ University of Sistan and Baluchestan, Zahedan, Iran; Email:marziyeh@ped.usb.ac.ir
}

Doi:10.5901/mjss.2016.v7n2s2p107

\section{Abstract}

\begin{abstract}
This study was conducted to predict managers' organizational productivity with regard to managerial talent and time management of school managers. This descriptive study followed a correlational design. The statistical population of the present study included all school managers in Jiroft. Using stratified random sampling method, 130 managers (65 females and 65 males) were selected as the sample. Measurement tools used in the current study were Talent Management Questionnaire (Oehley, 2007), Time Management Questionnaire (Azizi Moghaddam, 2006), and Managers' Organizational Productivity (Hersey and Goldsmith, 1998). The obtained evidence indicated these questionnaires' high validity and reliability. Statistical methods applied in this study included Pearson correlation coefficient, regression analysis and one-sample t-test. Results revealed that managerial talent and time management were significantly related to organizational productivity. Moreover, gender and level of education had no effects on organizational productivity.
\end{abstract}

Keywords: Organizational Productivity, Time Management, Managerial Talent.

\section{Introduction}

In the current world system, productivity and its improvement are considered among major objectives of active and alive organizations. In this challenging and progressive system, the main steps are identifying productivity and subsequently attempting to determine factors affecting its improvement. These steps can be regarded as essential conditions required for the realization of growth and development. Productivity is tied up with the survival and durability of a nation's life and is one of the criteria determining power in the international communities and scientific assemblies. In the world of productivity and huge capital investments, necessity of recognizing actual and potential abilities is one of the main priorities of administrative and executive system of our country to promote and expand it (Honari,et al,2006). In fact, productivity provides a realistic attitude towards work and life and is a measure through the aid of which the status quo can be continuously improved (Rahimnia,2009). With the increasing level of competition, technological complexity, speed of information exchange, and variety of tastes, the significance of productivity becomes evident. Productivity is increasingly based on knowledge, skills and abilities of mind of trained human beings. Expanded concept of productivity is not a fraction of output to data; however, it is a system of thought, a type of rational approach to life and a type of culture. A culture through applying which people can comply their thoughts, ideas, and deeds with values and realities, attempting to achieve the best material and spiritual results in life (Khodadadi,2010). Given that nowadays increasing efficiency and effectiveness are among the most important goals of any organization, managers' ability to deal with the existing time pressure and methods of controlling and managing time as well as his/her adherence to implement the organization's commitments to people and the type of services provided all influence efficiency and effectiveness. Among these mentioned changes, time and managing it are of significant importance (Jung, 2001). How managers decide to use their time appropriately is the core idea of time management theory. Accordingly, the main goals of managing time are avoiding wasting time and setting the working time (Koch and Kleimann, 2002). In this regard, Xiao-hua (2007) suggested that time management is firstly a requirement and can be considered as a good goal. Time management can be regarded as a vehicle which can transport humans and consequently the organizations in which they work from where they are to where they want to be (Tracy, 2006). Talent is a broad concept to the extent that it includes all or most physiological and psychological issues. Physical characteristics such as response speed, height, weight, agility, muscle strength, visual 
sensitivity, the ability to distinguish sounds and mental manifestations including spatial visualization, memory, speed of perception and reasoning can all be considered among the wide range of talents. Rahimnia ,Mortazavi and Delaram(2009) stated that management role is the most important factor affecting productivity. In addition, Capllor (2001) indicated that employing managers and specialists can affect productivity. The third millennium, a century in which we live, is the era of rapid changes. In such an atmosphere, organizations, especially educational organizations, must constantly be ready for changes and dealing with them. Since each organization is affected by its outer space, it should coordinate itself with developments otherwise there is no way to survive (Behrangi, 2004). Productivity is an accepted phenomenon in the manufacturing and service industries all around the world. To increase the level of productivity, large investments are made in manufacturing and service industries; however, given the importance and role of education in a society, the concept plays an inconspicuous role in education. Therefore, a series of objectives are considered to make it more appealing (Javam, 2001). To achieve these objectives, there is no choice but to resort to a systematic approach which includes time as well. Time is the most valuable asset of any individual, group, and organization that cannot be compared with any other funds in any way. Importance and priority of time have long attracted scholars' and scientists' attention such that to obtain a better understanding and to control time, some have struggled to forecast future and have broken down its boundaries. Time is irreplaceable, much too precious to waste, and limited, and cannot be borrowed or bought; thus, efficient use of time depends mostly on the awareness of how to spend and manage it (Abbasnejad, 2010). Nowadays, managers are considered as the main capital of any organization. A manager is the key factor that aids an organization to stay in the competition. With the complexity of the environment, the creation of diverse cultures and different types of jobs in organizations, gradually, the roles of managers and human resources have changed. These days, organizations need creative, flexible, and responsive managers. Organizations that are not able to cope with this path will be doomed to die. In this regard, what can guarantee organizations thriving and growing life is the existence of a strong and efficient management system. Other words, when managers have the required authority, they empower the organization, the positive results of which can be easily observed in the current situation of the organization. A delicate and decisive point is that when a manager is not capable and efficient, he/she cannot manage his/her subordinates and colleagues. In other words, lack of having the ability to perform the required measures leads to establishment of unofficial relations through which a manager attempts to solve issues and thus employees come out of their official duties and through making erroneous decisions, they endamage the whole system. Among organizations working at the society level is the Department of Education. In order to achieve its goals and objectives, all managers in various levels of this organization should be competent, capable and talented. Although all managers in the department of education, from minister to general managers, deputies and school managers have worked in this organization and known its structure, they must be chosen from among elites and people who have the required talent and ability to manage the organization (Ismaeili and Hosseini, 2011). Therefore, it is not surprising that in the current age, the term "elite" has spread among people who dispose knowledge, not land, as a means of production. Since, in the information age, the value of hard resources compared to other intangible resources, including knowledge, is sharply declining; hence, human capital, elites and talents in every society are recognized as the main known resources of modern societies. Through their better performance, top elites of a society distinguish the society in which they live in from other societies and this is why they are more focused on the people they employ rather than the strategies they apply. On the other hands, valuable talents are so rare. This growingly increases their importance. Moreover, retirement and withdrawal of capable and experienced workforce from the workplace, emerging skills requirements to achieve the desirable future, rapid changes of people's lifestyle all increase the importance of valuable talents (Delavar, 1997).

In a study entitled "Determining the Relationship between Cultural Intelligence and Managers' Productivity" conducted in schools in West Azerbaijan province, Hosseininasab and Ghaderi (2011) revealed that cultural intelligence and its components (metacognitive, cognitive, motivational and behavioral) were significantly correlated with managers' productivity. Moreover, the obtained results indicated that no significant relationship was found between variables of cultural intelligence and productivity with regard to demographic characteristics including years of experience, level of education, gender, and educational levels. Khadivi and Kalantari (2009), in a study entitled "Correlation between Managers' Creativity Skills (Creative Thinking) and Employees' Productivity", demonstrated that there was a significant correlation between managers' creativity and employees' productivity; however, with regard to employees' productivity, no significant difference was found considering their gender. Zaerian (2007), in a study entitled "The Effectiveness of Training Time Management Skills in Reducing Negligence of Managers and Employees of Department of Education in Tehran", concluded that there was a significant relationship between components of time management training and reducing managers' and employees' negligence. Zampetakis et al. (2010) carried out a study to examine the relationship between time management and the level of individual creativity and came into conclusion that time management, individual creativity and proposing innovative ideas were closely related to organizational culture and climate. In another 
study conducted by Johari et al. (2014) entitled "Identifying Indicators and Characteristics of Key Managers and Employees", the obtained results indicated that talented employees in an organization should be considered as one of the most important concepts in managing present and future human resources. Additionally, considering general features of managers, no significant difference was found with regard to gender; however, significant differences were found in terms of age and level of education. Randeria (2008) revealed that well-known international companies hire managers who not only have high intelligence quotient (emotional, affective ...), but also, considering physical and mental aspects, have higher capabilities compared to other managers. Since managers who have these abilities are more successful in performing their tasks.

Therefore, considering what was mentioned earlier and discussed theoretical and practical backgrounds, the objective of the current study was to determine the relationship of managerial talent and time management with school managers' organizational productivity. In addition, this study attempted to identify the level of predictability of managerial talent and time management in relation to productivity of school managers.

\section{Methods}

This descriptive study followed a correlational method. The statistical population included all elementary school managers of Jiroft in the academic year 20014-2015 whom were 196 individuals. According to the Morgan table, 130 individuals were selected as the sample of which 65 individuals were female managers and 65 individuals were male managers. Stratified random sampling method was used such that considering the number of males and females in the statistical population, the sample was selected.

\section{Measurement Tools}

Talent Management Questionnaire (Oehley, 2007): This scale was developed at the University of Stanley Bush by a student of Management (Marguerite Oehley) based on a study carried out to hire a number of managers who had the required abilities and talents to have managerial positions. This questionnaire measures eight components including the ability to think creatively, the ability to attract and employ talented staff, the ability to identify and distinguish employees who are commensurate with the job, the ability to develop and promote employees, the ability to give promotion and bonus to employees, the ability to create a balance between employees' work and life, the ability to establish good human relations with employees, and the ability to create challenging job opportunities for subordinates and employees. Each component consists of a few questions regarding the targeted component. This questionnaire entails 34 items in total. This is a Likert-type scale in which the responses range from never to always. The scale's content validity was confirmed by a number of management professionals. Moreover, the reliability of this questionnaire was examined using Cronbach's alpha coefficient the results of which was 0.80 , indicating its high reliability.

Time Management Questionnaire (Azizi Moghaddam, 2006): This four-point Likert type scale includes 43 items developed to measure skills related to time management and encompasses a four-point scale (Never, rarely, sometimes, and always). Each of these options has respectively 1, 2, 3, and 4 points. This questionnaire's developer, in a study carried out on high school teachers in Mahabad, reported that this scale have high content validity and reliability. Moreover, Malekara (2007) confirmed its high reliability. In this study, to examine its reliability, Cronbach's alpha coefficient was applied the result of which was 0.80 indicating its high reliability.

Managers' Organizational Productivity (Hersey and Goldsmith, 1998): This scale was designed by Hersey and Goldsmith in 1998 and contains 26 items and 7 subscales including ability, understanding, organizational support, motivation, feedback, credit, and compatibility. This is a five-point Likert type scale ranging from 1 (too little) to 5 (too much). The minimum possible score is 26 and the maximum score is 130 . Higher scores indicate manager's higher productivity. In a study conducted by Khodadadi et al (2010), alpha coefficient of this questionnaire was obtained 0.83 which is a desirable coefficient. The content validity of this questionnaire was confirmed by a number of management professionals. In addition, its reliability was examined through applying Cronbach's alpha coefficient and was 0.80 demonstrating its high reliability.

\section{Results}

\subsection{First Question: How is the status of time management from managers' perspective?}

To answer this question, one-sample t-test was used, the results of which are presented in Table 1. 
Table 1: Results of one-sample t-test in relation with time management

\begin{tabular}{|l|c|c|c|c|c|c|c|}
\hline Variable & Mean & $\mathrm{N}$ & $\mathrm{SD}$ & Test value & $\mathrm{T}$ & $\mathrm{df}$ & Sig \\
\hline Time Management & 2.19 & 130 & 0.28 & 2.5 & -12.22 & 129 & 0.001 \\
\hline
\end{tabular}

The results presented in table 1 indicate that time management with a mean of 2.19 is lower than the average which is 2.5 , indicating its undesirability among managers and is significant at the $99 \%$ confidence level $(P<0.01)$.

\subsection{Second Question: How is the status of Managerial talent from managers' perspective?}

To answer this question, one-sample t-test was applied.

Table 2: Results of one-sample t-test in relation with managerial talent

\begin{tabular}{|l|c|c|c|c|c|c|c|}
\hline Variable & Mean & $\mathrm{N}$ & $\mathrm{SD}$ & Test value & $\mathrm{T}$ & $\mathrm{df}$ & $\mathrm{Sig}$ \\
\hline Managerial talent & 2.89 & 130 & 0.53 & 3.5 & -12.95 & 129 & 0.001 \\
\hline
\end{tabular}

The results presented in table 2 indicate that managerial talent with a mean of 2.89 is lower than the average which respectively is 3.5 , indicating its undesirability among managers. The obtained results demonstrate that the mean on managerial talent is significant at the $99 \%$ confidence level $(P<0.01)$.

\subsection{Third Question: How is the status of organizational productivity from managers' perspective?}

To answer this question, one-sample t-test was used.

Table 3: Results of one-sample t-test in relation with organizational productivity

\begin{tabular}{|l|c|c|c|c|c|c|c|}
\hline Variable & Mean & $\mathrm{N}$ & $\mathrm{SD}$ & Test value & $\mathrm{T}$ & $\mathrm{df}$ & Sig \\
\hline Organizational productivity & 2.71 & 130 & 0.54 & 3 & -8.47 & 129 & 0.001 \\
\hline
\end{tabular}

The results presented in table 3 show that organizational productivity with a mean of 2.71 is lower than the average which is 3 , indicating its undesirability among managers and is significant at the $99 \%$ confidence level $(P<0.01)$.

\subsection{Fourth Question: Is there any significant relationship between managerial talent and organizational productivity?}

To examine this question, Pearson correlation coefficient was used.

Table 4: Examining the relationship between managerial talent and organizational productivity

\begin{tabular}{|l|c|c|}
\hline Variables & $\mathrm{R}$ & $\mathrm{Sig}$ \\
\hline Managerial talent & 0.364 & 0.001 \\
\cline { 1 - 2 } Organizational productivity & & \\
\hline
\end{tabular}

The results presented in the above table indicate that correlation coefficient between managerial talent and organizational productivity is 0.364 which is significant at the $99 \%$ confidence level.

\subsection{Fifth Question: Is there any significant relationship between time management and organizational productivity?}

To examine this question, Pearson correlation coefficient was used.

Table 5: Examining the relationship between time management and organizational productivity

\begin{tabular}{|l|c|c|}
\hline Variables & $\mathrm{R}$ & $\mathrm{Sig}$ \\
\hline Time management & 0.523 & 0.001 \\
\hline Organizational productivity & \\
\hline
\end{tabular}


The results presented in the above table reveal that correlation coefficient between time management and organizational productivity is 0.523 which is significant at the $99 \%$ confidence level.

\subsection{Sixth Question: Can managerial talent predict organizational productivity?}

To answer this question, regression analysis was used.

Table 6: Summary of the regression model of the variable predicting organizational productivity

\begin{tabular}{|l|c|c|c|c|c|}
\hline Variable & $\mathrm{R}^{2}$ & $\mathrm{~F}$ & $\mathrm{~B}$ & $\mathrm{~T}$ & $\mathrm{sig}$ \\
\hline Organizational productivity & 0.126 & 19.54 & 0.364 & 4.42 & 0.001 \\
\hline
\end{tabular}

These results indicate that the variable of managerial talent predicts $12 \%$ of the variance in organizational productivity. In this model,the standard beta is 0.364 and the correlation is significant at the $99 \%$ confidence level.

\subsection{Seventh Question: Can time management predict organizational productivity?}

To answer this question, regression analysis was used.

Table 7: Summary of the regression model of the variable predicting organizational productivity

\begin{tabular}{|l|l|l|l|l|l|}
\hline Variable & $\mathrm{R}^{2}$ & $\mathrm{~F}$ & $\mathrm{~B}$ & $\mathrm{~T}$ & $\mathrm{Sig}$ \\
\hline Organizational productivity & 0.268 & 46.11 & 0.523 & 6.93 & 0.000 \\
\hline
\end{tabular}

These results indicate that the variable of time management predicts $26 \%$ of the variance in organizational productivity. In this model,the standard beta is 0.523 and the correlation is significant at the $99 \%$ confidence level.

\subsection{Eight Question: Is there any significant difference in time management considering managers' gender?}

Table 8: Evaluating the difference in manager's time management with regard to gender

\begin{tabular}{|l|c|c|c|c|c|c|c|}
\hline Variables & gender & number & Mean & SD & T & df & Sig \\
\hline \multirow{2}{*}{ Time management } & Male & 65 & 2.20 & 0.28 & 0.616 & 128 & 0.53 \\
\cline { 2 - 8 } & Female & 65 & 2.16 & 0.27 & & & \\
\hline
\end{tabular}

The results represented in the above table demonstrate that male managers' mean on time management is 2.20 with the standard deviation of 0.28 and female managers' mean is 2.16 with the standard deviation of 027 . Moreover, these results indicate that the calculated $\mathrm{T}$ is 0.616 with the degree of freedom of 128 which is not significant at the $95 \%$ confidence level. Therefore, it can be concluded that the levels of time management in male and female managers are alike and the considered hypothesis is rejected.

\subsection{Ninth Question: Is there any significant difference in managerial talent considering managers' gender?}

Table 9: Evaluating the difference in manager's managerial talent with regard to gender

\begin{tabular}{|l|c|c|c|c|c|c|c|}
\hline Variables & gender & number & Mean & SD & T & df & Sig \\
\hline \multirow{2}{*}{ Managerial talent } & Male & 65 & 2.88 & 0.54 & -0.511 & 128 & 0.61 \\
\cline { 2 - 6 } & Female & 65 & 2.94 & 0.48 & & & \\
\hline
\end{tabular}

The results represented in the above table demonstrate that male managers' mean on managerial talent is 2.88 with the standard deviation of 0.54 and female managers' mean is 2.94 with the standard deviation of 0.48 . Moreover, these results indicate that the calculated $\mathrm{T}$ is -0.511 with the degree of freedom of 128 which is not significant at the $95 \%$ confidence level. Therefore, it can be concluded that the levels of male and female managers' managerial talent are alike and the considered hypothesis is rejected. 


\subsection{Tenth Question: Is there any significant difference in organizational productivity considering gender?}

Table 10: Evaluating the difference in productivity of human resources with regard to gender

\begin{tabular}{|l|c|c|c|c|c|c|c|}
\hline Variables & gender & Number & Mean & SD & T & Df & Sig \\
\hline \multirow{2}{*}{ organizational productivity } & Male & 65 & 2.70 & 0.55 & -0.411 & 128 & 0.68 \\
\cline { 2 - 8 } & Female & 65 & 2.74 & 0.49 & & & \\
\hline
\end{tabular}

The results represented in the above table demonstrate that male managers' mean on productivity of human resources is 2.70 with the standard deviation of 0.55 and female managers' mean is 2.74 with the standard deviation of 0.49 . Moreover, these results indicate that the calculated $\mathrm{T}$ is -0.831 with the degree of freedom of 128 which is not significant at the $95 \%$ confidence level. Therefore, it can be concluded that the levels of productivity of human resources among male and female managers are alike and the considered hypothesis is rejected.

\section{Discussion and Conclusion}

The present study aimed to determine the predictive role of managerial talent and time management in relation with managers' organizational productivity. The results demonstrated in Table 1 indicated that the undesirability of time management from managers' perspectives. This indicated that managers with higher ability to think creatively, social intelligence, organizational intelligence, cultural intelligence, ability to attract and hire employees, ability to develop and promote employees and greater human relations in the organization, compared to other managers in other organizations, had higher levels of productivity. Therefore, it can be concluded that a manager who is able to control and manage time can control the environment and the organization much better. These results are in line with the results of some previously conducted studies including Kearns and Gardiner (2007) who indicated the effects of time management on managers' self-efficacy and productivity.

With regard to the status of managers' managerial talent, the obtained results presented in Table 2 demonstrated the undesirability of managerial talent from managers' perspectives. Indeed, these results indicated the key role of managerial talent and its positive effects on managers' cognitive, emotional, and behavioral aspects aiding them to manage the organization much better. The obtained results represented in this table revealed that there was a correlation between managerial talent and organizational productivity. This means that managers with higher ability to think creatively, social intelligence, organizational intelligence, cultural intelligence, ability to attract and hire employees, ability to develop and promote employees and greater human relations in the organization, compared to other managers in other organizations, had higher levels of productivity. It seems that managers who have these abilities are able to establish useful relations with the environment around them and can analyze it much better. These results are in line with the results of Moshabaki and Tizro (2009) who revealed that managers' cultural intelligence was significantly and strongly related to features of entrepreneurs.

The third question was aimed to examine the status of managers' organizational productivity. The obtained results presented in Table 3 indicated the undesirability of productivity from managers' perspective. In fact, this result revealed managers' optimum satisfaction with the methods of conducting the job, organizational structure, ability to work, managerial spirit, targeted planning, and good used of time that is time management.

Considering the relationship between managerial talent and organizational productivity, results demonstrated in Table 4 revealed that correlational coefficient between managerial management and organizational productivity was significant at the $99 \%$ confidence level. However, this finding is consistent with the results of previously conducted studies, since employing creative and capable managers is among factors affecting organizational productivity and has great impacts on development, growth, and increasing efficiency and productivity. Nowadays, organizations have fully realized that they have to employ the best managers and employees in order to achieve success in the complex global environment and also sustainability in the business environment. Financial resources are limited what is important and critical is possessing talents and empowered managers which can not only be a competitive advantage, but also can compensate for the lack of resources or other defects. The accuracy of these results can be fully confirmed through comparing them with the results of previously conducted studies. In another study conducted by Johari et al. (2014) entitled "Identifying Indicators and Characteristics of Key Managers and Employees", the obtained results indicated that talented employees in an organization should be considered as one of the most important concepts in managing present and future human resources. Additionally, in a study conducted abroad by Smith (2005), the results showed that managers with high intelligence capabilities have considerable superiority over others in perceiving organizational 
problems, understanding learning and acquisition of knowledge, and improving occupational performance. Although the obtained results are not consistent with the results of other studies, it cannot be concluded that there was no significant correlation between managerial talent and organizational productivity. This probably indicates that the considered organization do not pay sufficient attention to the concept of talent, its components and their impacts on the organization.

With regard to the question that whether there is a significant relationship between time management and organizational productivity, the results demonstrated in Table 5 showed that correlational coefficient between time management and organizational productivity was significant at the $99 \%$ confidence level. Managers should create fundamental changes in skills and techniques of managing various matters in order to survive in the dynamic and changing environment of today's organizations. Time and managing it are among these skills. Given the fact that increasing efficacy and effectiveness are considered among the most important goals of any organization and managers' ability in confronting with the existing time pressure and controlling and managing time are among factors affecting this efficacy and effectiveness. In fact, the obtained findings are in line with the results of studies carried out to examine the relationship between time management and organizational productivity. In a study entitled "Work Measurement and Standards with the Approach to Improve the Organizational Productivity" in 2013, findings revealed that timing aids managers to enhance productivity and effectiveness in the organization. This indicates that there was a significant relationship between time management and organizational productivity.

The results in Table 6 showed that the variable of talent predicted organizational productivity. Findings revealed that there was a significant correlation between talent and organizational productivity indicating that talents managers who have managerial components to manage an organization are more capable of achieving better human resources' productivity compared to other managers. This results is in line with the results of a study conducted by Zaerian (2007)which indicated that there was a mutual and significant relationship between managers' creativity and their abilities to solve issues in the work. The more the managers' level of creativity, the higher their ability to solve various problems. Moreover, this finding is consistent with the results of Johari et al. (2014) indicating that talented employees in an organization should be considered as one of the most important concepts in managing present and future human resources.

In addition, the results presented in Table 7 indicated that time management predicted organizational productivity. It can be concluded that time management includes a series of abilities and skills that aids managers and employees to control time optimally in order to apply resources and facilities more appropriately. In fact, time management entails behaviors aiming at effective application of time during the implementation of certain targeted activities. The results in this table showed that one of the necessary conditions for being effective in an organization is managers' ability to apply time management skills, lack of which leads to low performance, creates a sense of purposelessness and depression among managers and ultimately hinders the achievement of the most important organizational goal that is organizational productivity. These results are in line with the results of Mahboudi (2006), entitled "Examining the Relationship between Organizational Skill of Time Management and Effectiveness of Managers in Shiraz", and Naghizadeh (2008), entitled "The Relationship between Time Management and Occupational Stress in Managers and Employees of Physical Education Offices in South Khorasan Province".

Examining the difference in managerial talent of male and female managers, the results in Table 8 demonstrated that managerial talents of male and female managers were alike, indicating that the considered hypothesis was rejected. This findings is in line with the results of Johari et al. (2014) that identified indicators and characteristics of key managers and employees. The obtained results identified 115 features of key and talented employees among which 96 features were considered general and 19 features were classified as special features. General features included emotional intelligence and personal characteristics and special features included behavioral characteristics, executive management skills, innovativeness, idealism of learners, knowing the law, and expertise. The results showed that talented employees in an organization should be considered as an important concept in the current and future human resources management. Moreover, considering general features of managers, no significant difference was found with regard to gender. However, in terms of age and level of education, significant differences were observed. These findings are not consistent with the results of Ismaeili and Hosseini ( 2011),entitled 'The Relationship between Managers' Emotional Intelligence and Their Ability to Attract Elementary School Teachers' Trust", the results of which indicated that there was a positive relationship between trust and emotional intelligence. In addition, considering their level of education, there was no significant difference between managers' emotional intelligence and talent. However, there was a significant difference among managers' emotional intelligence with regard to gender.

The results presented in Table 9 indicated that the levels of time management of male and female managers were alike. Without doubt, the greatest asset of any human being and any organization is time. Time is gold, nothing takes it place, it has no replacement and its importance is crystal clear for all human beings and organizations. Whether they are 
males or females, employed or unemployed, they work for Department of Education or any other organization, what makes a difference in this respects is the way they apply, use and manage time. All people whether male or female are capable of using and managing time. Moreover, the results of a study conducted in Japan showed that male and female managers do not differ in terms of methods they apply to manage time. However, the effects of gender on other aspects of time management was observed. In fact, the main difference in applying time among male and female managers was the amount of time they had spent on conducting activities outside the workplace and home. Starting a family and having children have great impacts on people's time.

Finally, examining the difference in productivity among male and female managers, the results in Table 10 indicated that the levels of productivity of male and female managers were alike. This finding is in line with the results of Abbasnejad( 2010), who concluded that gender had no significant effects on efficacy of specialists at the level of Higher Education. Moreover, Khadivi and Kalantari concluded that there was a significant correlation between creativity and employees' productivity; however, no significant difference was found between male and female employees considering their productivity. The results of the current study showed that considering managers' level of education, the levels of productivity of human resources were alike. This finding is consistent with the results of Rahimnia., Mortazavi and Delaram (2009) who concluded that the levels of performance feedback, age, gender, years of experience, level of education, and types of employment had no relationship with the level of employees' productivity. Moreover, in a study entitled "Determining the Relationship between Cultural Intelligence and Managers' Productivity" conducted in schools in West Azerbaijan province, Hosseininasab and Ghaderi (2011) concluded that no significant relationship was found between variables of cultural intelligence and productivity with regard to demographic characteristics including years of experience, level of education, gender, and educational levels. This finding is consistent with the obtained results in the current study. Findings showed that components of managerial talent are among key factors which can lead to success and authority and capability are important factors in managing an organization which can improve the current situation of the organization. Additionally, the findings indicated that managers' managerial capabilities and time management were significantly and positively related to organizational productivity. This relationship can be explained in this way that the root cause of productivity is the manager's ability to appropriately manage time.

The present study provided an attractive landscape on the required abilities and capabilities of managers to properly manage time and ultimately reach organizational productivity. Examining the obtained results indicated the relationship of the required components of managerial talent and time management with organizational productivity and also other dimensions and components of managers' development (personal characteristics, gender features, and the required levels of education for managers) and provided valuable points on the issue.

It is recommended that managers be rated based on years of experience, level of education and their performance and be selected among local people using a systematic evaluation criteria needed to determine managers' qualification for managerial positions and be chosen without any bias.

\section{References}

Abbasnejad, I. (2010). Relationship between time management and job stress among teachers of physical education in Mashe, thesis. Behrangi, M.R. (2004). Educational and School Management. Fourth Edition. Tehran: Kamal-e-Tarbiat Publication.

Capllor,B.(2001). Efficency factors the Personels, public:MC Grow Hill.

Delavar, A. (1997). Theoretical and practical fundamentals of research in humanities and social sciences. Second Edition. Tehran: Roshd Publication.

Honari, H., Rezaeeian, A., Kozechian, H., and Ehsani, M. (2006). The relationship between motivation and human resources' productivity in the Physical Education Organization of the Islamic Republic of Iran. Motion, 27.

Hosseininasab, D., and Ghaderi, V. (2011). Determining the relationship between cultural intelligence and productivity of school principals in West Azerbaijan, Faculty of Educational Sciences, West Azerbaijan, 4(13), 27-44.

Ismaeili, B., and Hosseini, H. (2011) Examining the relationship of skills and abilities with management roles. Journal of New Approach to Educational Management, 1(13).

Javam, M.H. (2001). Educational management and Familiarity with Department of Education. Tehran: Soroush Publication.

Kearns, H., \& Gardiner, M. (2007). Is it time well spent? The relationship between time management related behaviors, perceived effectiveness and work related moral \& distress in a university context. Higher education Research and Development, 26(2), 235247.

Khadivi, A., and Kalantari, R. (2009). Correlation between managers' creativity skills (creative thinking) and employees' productivity. Poyesh,1(3,4),27-46.

Khodadadi, M.R., Kashef, M.M., Salehzadeh, K., Shirmohammadzadeh, M., Khoshnevis, F. (2010). The relationship between organizational intelligence and productivity of managers of Physical Education in East Azerbaijan province. Journal of Sports Management. 
Koch, C.J., and Kleinmann, M. (2000). A stich in time saves nine: Behavioral decision making explanations for time management problems. European Journal of Work \& Organizational Psychology, 11, 199-217.

Mahboudi, M.H. (2006). Examining the relationship between organizational skill of time management and effectiveness of managers in Shiraz. MA Thesis, University of Shiraz.

Malekara, B. (2007). Examine the relationship between time management and job burnout in the General Office of Urmia Tax Affairs in the fiscal year. MA Thesis of Governmental Management, Management and Planning Organization of West Azerbaijan province.

Moshabaki, A., and Tizro, A. (2009). The effects of emotional intelligence and cultural intelligence on the success of the global leaders. Research management, 2(3), 53-73.

Naghizadeh, H. (2008). The relationship between time management and occupational stress in managers and employees of Physical Education Offices in South Khorasan province. Proceedings of the First National Conference on Management.

Rahimnia, F., Mortazavi, S., and Delaram, T. (2009). Examining the effects of cultural intelligence on task performance among managers (case study: branches of EN Bank in Tehran). Future management, 8(22).

Randeria, H. (2008). What is more important IQ or EQ? The Global Educator. Available at: global\&@imsindia.com

Tracy, B. (2006). Time is gold (translated by: E'tezadi, M.D.). Third edition. Tehran: Rashin Publication.

Xiao-hua, Y. (2007). Developing time-management skills in the foreign language classroom4, 6 (serial No.42).

Zaerian, Z. (2007). The effectiveness of training time management skills in reducing negligence of employees of Department of Education in Tehran. MA Thesis, Allameh Tabatabai University.

Zampetakis, L. A., Bouranta, N., \& Moustakis, V. S. (2010). On the relationship between individual creativity and time management. Journal of thinking skills and creativity, 5 (1), 23- 32. 